\title{
Editorial
}

\section{Es tiempo de una nueva mentalidad empresarial}

\section{GIOVANNY CARDONA MONTOYA*}

Los empresarios y sus organizaciones viven una era compleja. La pervivencia y crecimiento de las empresas se hallan marcados por una compleja triada sin la cual no se podría hablar de un desarrollo sostenible en el presente, a saber: viabilidad financiera, social y ambiental.

El punto de quiebre que provoca el cierre de una época y el inicio de otra se denomina "cambio climático". A pesar de que la sociedad lleva cerca de medio siglo recibiendo señales sobre la crisis medioambiental, es ahora cuando estas han adquirido una dimensión dramática. Y no solo se trata de percepciones preocupantes sobre la agudización del problema sino, especialmente, de advertencias claras por parte de la comunidad científica.

La sociedad en general y las empresas en particular hemos perdido un tiempo precioso. Por siglos la humanidad asumió que la producción empresarial, el intercambio de bienes y su consumo implicaban solo los costos mesurables en la dimensión microeconómica. Las cuentas ambientales eran, en el mejor de los casos, del resorte del sector público; y en el peor, un embeleco de los académicos.

La complicidad social, política y económica sirvió para que la humanidad hiciera caso omiso a los impactos ambientales del sistema económico (deterioro de la calidad del aire y del agua, reducción dramática de bosques entre otros).
COMO CITAR ESTE ARTÍCULO

How to cite this article:

Cardona, G. (2019). Editorial. Es tiempo de una nueva mentalidad empresarial. Revista Perspectiva Empresarial, 6(2), 3-4.

\footnotetext{
* Doctor en Ciencias Pedagógicas. Vicerrector Académico. CEIPA, Business School, Sabaneta, Colombia. E-mail: giovanny.cardona@ceipa.edu.co. ORCID: 0000-0003-2253-3580. Google Scholar: https://scholar.google.es/ citations? user=moBCyBEAAAAJ\&hl=es.
} 
Pero esa era ha terminado. La humanidad se halla en la encrucijada de su futuro. La época en que señalábamos que "no heredamos la tierra de nuestros abuelos sino que la tomamos prestada de nuestros nietos", se ha agotado. El planeta se desmorona ante nuestros ojos. ¡Es hora de actuar!

La nueva concepción de desarrollo sostenible obliga a las empresas a verse más sistémicas, menos atomizadas. Aunque la economía de mercado se fundamenta en la competencia entre organizaciones creadas bajo la propiedad privada, estas no pueden seguirse viendo como islas separadas por un mar al que le son indiferentes. Todos hacemos parte del mismo sistema vital.

La competitividad de la empresa del futuro -del futuro cercano- se logrará en el marco de procesos de innovación que permitan alcanzar la viabilidad financiera, sin menguar la calidad de su entorno vital (agua, aire y otras especies vivas). No hay espacio para rentabilizar negocios que sigan destruyendo el planeta. Ya no hay territorio para esta lógica mercantil. Las innovaciones deben basarse en la simbiosis entre lo privado y lo público: hacer negocios privados que produzcan bienes ambientales de carácter público.

En ese contexto, aparece la tercera columna del nuevo paradigma de desarrollo: la dimensión social.

El crecimiento económico de las últimas décadas se ha alcanzado, a pesar de que cerca de dos millares de habitantes del planeta han sido segregados del desarrollo alcanzado. La informalidad, el desempleo y la falta de oportunidades básicas para millones de personas no han sido óbice para que países y empresas continúen la senda del enriquecimiento económico.

Pero no solo porque no hay una ética que justifique semejante segregación en el mundo de hoy -basado en la ciencia, la racionalidad y la innovación-, sino también porque la pobreza es caldo de cultivo para un mayor deterioro ambiental (por ejemplo, quemas indiscriminadas de bosques, cacería descontrolada, minería informal e ilegal, utilización de tecnologías obsoletas).
En suma, solo empresas creativas e innovadoras que combinen la rentabilidad financiera con la sostenibilidad ambiental y la inclusión social podrán ser agentes de cambio ante el reto venidero: "el desarrollo sostenible de los próximos lustros". 